\title{
Vacation (after-) effects on employee health and well-being, and the role of vacation activities, experiences and sleep
}

\author{
Jessica de Bloom • Sabine A. E. Geurts • Michiel A. J. Kompier
}

Published online: 12 May 2012

(C) The Author(s) 2012. This article is published with open access at Springerlink.com

\begin{abstract}
Most vacations seem to have strong, but rather short-lived effects on health and well-being $(\mathrm{H} \& \mathrm{~W})$. However, the recovery-potential of relatively long vacations and the underlying processes have been disregarded. Therefore, our study focused on vacations longer than 14 days and on the psychological processes associated with such a long respite from work. In the present study, we investigated (1) how health and well-being (H\&W) develop during and after a long summer vacation, (2) whether changes in $\mathrm{H} \& \mathrm{~W}$ during and after vacation relate to vacation activities and experiences and (3) whether changes in $\mathrm{H} \& \mathrm{~W}$ during and after vacation relate to sleep. Fifty-four employees reported their H\&W before, three or four times during and five times after vacation. Vacations lasted 23 days on average. Information on vacation experiences, work-related activities and sleep was collected during vacation. Vacation activities were assessed immediately after vacation. $\mathrm{H} \& \mathrm{~W}$ increased quickly during vacation, peaked on the eighth vacation day and had rapidly returned to baseline level within the first week of work resumption. Vacation duration and most vacation activities were only weakly associated with $\mathrm{H} \& \mathrm{~W}$ changes during and after vacation. Engagement in passive activities, savoring, pleasure derived from activities, relaxation, control and sleep showed strong relations with improved $\mathrm{H} \& \mathrm{~W}$ during and to a lesser degree after vacation. In conclusion, $\mathrm{H} \& \mathrm{~W}$ improved during long summer vacations, but this positive effect was short-lived. Vacation experiences, especially pleasure, relaxation, savoring and control, seem to be especially important for the strength and persistence of vacation (after-) effects.
\end{abstract}

Keywords Holiday $\cdot$ Recovery $\cdot$ Respite $\cdot$ Work $\cdot$ Stress $\cdot$ Positive psychology

J. de Bloom $(\varangle)$ - S. A. E. Geurts · M. A. J. Kompier

Department of Work and Organizational Psychology, Behavioural Science Institute, Radboud

University Nijmegen, P.O. Box 9104, 6500 HE Nijmegen, The Netherlands

e-mail: j.debloom@gmail.com 


\section{Introduction}

Do we need vacations? And how long should a vacation be? In an article of the New York Times in 1910, William Taft, 27th president of the US stated "[...] 2 or 3 months' vacation $[\ldots]$ are necessary in order to continue work the next year with that energy and effectiveness which it ought to have." ("How long should a man's vacation be?," 1910, July 31). Today, the discussion about the benefits of vacations is still ongoing, evident in the fact that many countries worldwide (including the US) have not established national vacation rights. Is the answer to these questions still missing? And besides the ideal length, which factors determine the extent of "energy and effectiveness" we bring along to our work after vacation?

According to Effort-Recovery Theory (Meijman and Mulder 1998), effort expenditure associated with working has certain psycho-physiological costs or load effects (e.g., fatigue). When these load-effects are intensive, for instance when workers are regularly exposed to demanding and stressful situations at work, and recovery in-between work periods is incomplete, health and well-being are jeopardized (e.g. Belkic et al. 2004; Härma 2006). Consequently, recurrent and complete recovery from work is crucial to prevent adverse effects on health and well-being (H\&W).

Employees are often unable to recover sufficiently during short respites from work due to increasingly permeable boundaries between work and home domains, long working hours, working overtime and prolonged physiological activation as a result of pre-occupation with work, (e.g. Fritz and Sonnentag 2005; Van Hooff et al. 2007a; Akerstedt 2006). Therefore, a longer period away from work may be needed to fully recover from work (Dahlgren et al. 2005). Vacations represent the longest period of temporary absence from work and may, therefore, constitute a more powerful respite opportunity than shorter rest intervals.

Earlier studies found that vacationing was associated with higher life satisfaction (e.g. Lounsbury and Hoopes 1986), better mood (e.g. Nawijn et al. 2010; Strauss-Blasche et al. 2000), lower levels of health complaints (e.g. Fritz and Sonnentag 2006) and lower levels of exhaustion after vacation (e.g. Kühnel and Sonnentag 2011; Westman and Eden 1997). However, these positive vacation effects seemed to be short-lived and disappeared rapidly after work resumption (De Bloom et al. 2009).

Following Taft's argumentation, it may actually be possible that the length of earlier vacations under investigation was too short to resume work with increased energy levels. If this was true, longer vacations should have stronger and longer lasting effects.

Regarding the relationship between vacation duration and the strength and persistence of vacation effects, Lounsbury and Hoopes (1986) found no effect of vacation length on job satisfaction, job involvement, organizational commitment, turnover intention and life satisfaction. The median length of the vacations they investigated was 7 days and only $6 \%$ of the sample went on vacation for more than 14 days. Etzion (2003) found similar levels of job stress and burnout in vacationers who went on short (7-10 days) or long vacations (more than 10 days, mean duration and range not reported). Kemp et al. (2008) also reported no relationship between holiday duration and happiness in vacations ranging from 4 to 14 days (mean 7.5 days). In a similar vein, Nawijn (2010) found no duration effects on mood in vacations ranging from 2 to 17 days (mean not reported). Recently, De Bloom et al. (2010) detected no differences in $\mathrm{H} \& \mathrm{~W}$ changes during and after vacation in vacationers who went on holidays for 4.5 or 9 days respectively. Until now, StraussBlasche et al. (2000) were the only researchers who found moderate and positive associations between 'days away from home' and feeling recuperated after a 14-day respite from work. Hence, whilst it seems theoretically plausible to expect a positive relationship 
between vacation length and $\mathrm{H} \& \mathrm{~W}$ changes, the small number of earlier studies generally did not reveal convincing associations.

However, the vacations examined in the aforementioned studies were mostly shorter than 14 days. So, it could be that most of the vacations studies thus far were simply not long enough for vacation length to make a difference. In order to examine the value of an extended recovery period, our study will therefore focus on changes in $\mathrm{H} \& \mathrm{~W}$ during and after vacations longer than 14 days. Our first research question is:

\section{How do $\mathrm{H} \& \mathrm{~W}$ develop during and after a long summer vacation ( $>14$ days)?}

An important clue in determining the effects of vacation is to study the development of $\mathrm{H} \& \mathrm{~W}$ within a vacation period. Until now, few vacation studies incorporated measurements during vacation. In a cross-sectional study (Nawijn 2010), tourists in the Netherlands filled in a self-report questionnaire on well-being. Individual scores at different time stages during vacation were then compared. Vacationers' mood was generally high during vacation, but lower in the beginning of the holiday period. Mood levels of vacationers in the "core phase" of vacation (defined as the medial $70 \%$ of the vacation) were highest. Towards the end of the vacation period, mood was lower than during the core phase. In our study, we will test whether these trends also apply longitudinally.

So far, a vacation has merely been conceived as the possibility to prevent a deficient state: during stressful working periods employee' H\&W decrease and adverse effects need to be compensated for by taking a vacation. This argumentation fits into the passive mechanism underlying recovery: the mere absence from work strain is expected to lead to recovery (Geurts and Sonnentag 2006). However, it can be hypothesized that vacation not only 'repairs' H\&W but also adds something positive to it (i.e. builds resources), representing the active mechanism underlying vacation (De Bloom et al. 2010; Geurts and Sonnentag 2006).

Suppositions of Broaden- and Build Theory (Fredrickson 2001) and Self-Determination Theory (Ryan and Deci 2000) may account for this active mechanism (De Bloom et al. 2010). Positive experiences associated with vacationing (e.g. pleasure derived from activities, relaxation) may broaden people's thought and action repertoires and build personal resources like creativity, skills and social support. The fulfillment of the fundamental human needs for autonomy and relatedness during a holiday with family and friends may also increase well-being and lead to persisting effects (De Bloom et al. 2010; De Bloom et al. in press; Ryan et al. 2010).

Following this argumentation, in vacation research, a vacation should no longer be considered merely a control occasion for the absence of work stress (Eden 2001). From a work psychological perspective, it is essential to open up the black box of vacationing and to study what vacationers actually do and experience during vacation. Engagement in pleasant activities and positive experiences like psychological detachment, relaxation and control may well determine the benefits of vacations. Psychological detachment refers to mentally distancing oneself from recent work demands, relaxation stands for a state of low activation and low tension, often resulting from low-effort activities and control refers to autonomy over time and activities (Etzion et al. 1998; Fritz et al. 2010; Sonnentag and Fritz 2007).

Studies on the effect of specific leisure time and vacation activities are scarce and the results are yet inconclusive (e.g. Fritz and Sonnentag 2005; Rook and Zijlstra 2006). This raises the question whether the specific nature of activities people engage in is important or whether it is may be more important that leisure activities are experienced as enjoyable and match individual preferences (Pressman et al. 2009; Tucker et al. 2008). Therefore, our second research question is: 
2. How do vacation activities and experiences relate to changes in $\mathrm{H} \& \mathrm{~W}$ during and after vacation?

The current study will focus on four common types of vacation activities, that is workrelated, physical, social and passive activities. Regarding vacation experiences, we concentrate on experiences that appeared to be related to $\mathrm{H} \& \mathrm{~W}$ in earlier recovery research (De Bloom et al. 2009; Fritz et al. 2010; Van Hooff et al. 2011): pleasure derived from leisure activities, psychological detachment from work, relaxation and control over leisure time.

Additionally, we will investigate a factor that has not yet been investigated in relation to $\mathrm{H} \& \mathrm{~W}$ changes across vacations: savoring. Savoring refers to "[...] processes through which people actively derive pleasure and fulfillment in relation to positive experiences" (Bryant and Veroff 2007). For most people, vacationing is a positive life experience and holidays may therefore constitute an opportunity par excellence to savor. This in turn is expected to increase $\mathrm{H} \& \mathrm{~W}$ during and after vacation.

Besides an opportunity to engage in recovering activities and go through positive experiences, a vacation may also contribute to recovery because it provides an opportunity for a good night's sleep. Sleep fulfills a major restorative function (Akerstedt et al. 2009) and sleep deprivation negatively affects physical and mental well-being (Nilsson et al. 2001; Wheaton et al. 2011). Optimal sleepers report lower levels of depression and anxiety, face lower accident risks, and experience higher levels of self-esteem, personal growth, positive relations with others, purpose in life, and work satisfaction (Hamilton et al. 2007; Leger et al. 2006). Groeger et al. (2004) found that employees generally sleep less on workdays than on non-workdays which may, at least partly, be due to prolonged physiological activation resulting from work stress (Akerstedt et al. 2009). Vacation as a period of absence from work and work stressors may thus be an occasion for workers to sleep well. Moreover, workers do not have to get up early for work and can sleep in if they went to bed late. Consequently, our third research question is:

3. How do sleep duration and sleep quality during vacation relate to changes in $\mathrm{H} \& \mathrm{~W}$ during and after vacation?

The objective of the present study is twofold. First, we aim to replicate previous research regarding vacation (after-) effects on $\mathrm{H} \& \mathrm{~W}$ and the role of vacation activities and experiences in a special type of vacation: a long summer vacation ( $>14$ days). Second, we seek to extend current knowledge by focusing on (1) detailed developments in $\mathrm{H} \& \mathrm{~W}$ during long vacations and (2) the role of three variables that have hardly received attention in vacation research yet and that may affect the strength and persistence of vacation effects: vacation duration, savoring and sleep.

\section{Method}

\subsection{Procedure}

Table 1 presents our longitudinal research design. Data were collected on ten occasions: one before vacation, three or four during vacation and five after vacation. In addition, 3 weeks before vacation, the participants filled in a general questionnaire with questions regarding demographics (e.g. age, marital status, education), basic job information (e.g. weekly work hours) and vacation characteristics (e.g. planned vacation duration and destination). 


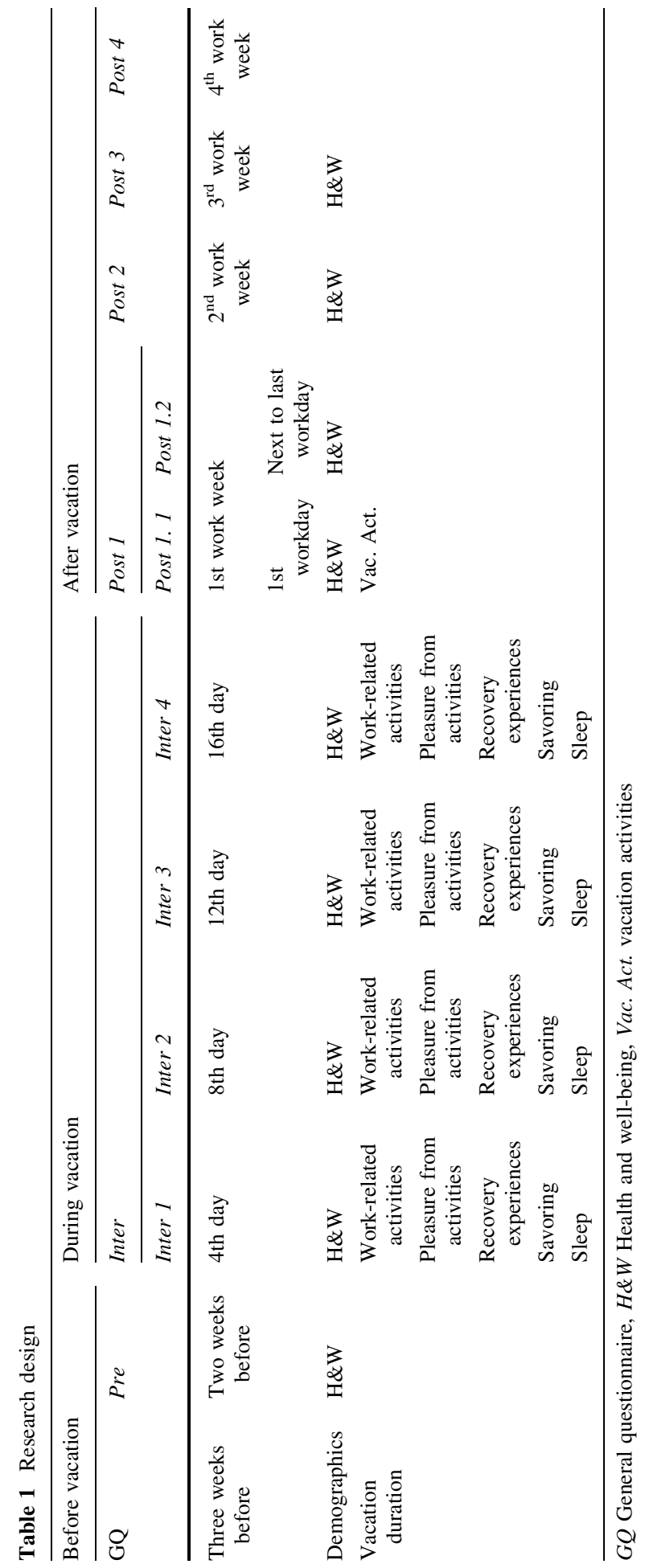


We took several steps to reduce non-response as suggested by Newman (2009). For example, each participant got a tailor-made time schedule of his/her individual measurement occasions and each measurement was preceded by a reminder (an email and a cell phone text message). Before and after vacation, participants were asked to fill in online diaries directly before going to bed, for which they received an individual log-in code.

The baseline measure of $\mathrm{H} \& \mathrm{~W}$ (Pre) was scheduled 2 weeks prior to vacation, because measurements immediately before vacation may be biased either looking forward to vacation (Gilbert and Abdullah 2002; Nawijn et al. 2010) and/or pre-vacation work stress (DeFrank et al. 2000; Westman 2005).

Before the participants went on vacation, they received a cell phone with a prepaid SIMcard. During vacation, the participants were contacted for an interview on the provided cell phone between 5 and 8 p.m. at least three times: on the 4th (Inter 1), 8th (Inter 2), and 12th day (Inter 3 ) after the start of vacation. Participants whose vacation lasted more than 16 days were also contacted on the 16th day (Inter 4). If participants could not be phoned, a text message was sent wherein they were asked to open their 'emergency envelop', containing paper versions of the telephone interviews and to fill in one of these questionnaires. On each measurement occasion, four or five participants made use of this possibility. Analyses demonstrated that there were no systematic differences in $\mathrm{H} \& \mathrm{~W}$ during vacation between participants who filled in questionnaires and those who were interviewed by telephone. Most of the participants went on a vacation for 2-3 weeks. The mean duration of vacation was 23 days (range 15-34 days). Most participants went on vacation to France (24\%), $13 \%$ went on holidays in the Netherlands, $9 \%$ went to Austria, $7 \%$ to Germany and the same percentage to Italy. The remaining participants spent their vacation in other countries.

After vacation, the participants were asked to fill in online diaries on five different occasions: on their first work day (Post 1.1), on the next to last day of their first week of work resumption (Post 1.2), and on Tuesdays during the 2nd (Post 2), 3rd, (Post 3) and 4th (Post 4) week of work resumption.

After completion of the data collection, participants were thanked for their participation and informed about when preliminary results were expected.

\subsection{Participants}

To recruit participants, flyers were handed out and ads were printed in two local newspapers. To encourage participation, three lottery prices were announced as an incentive: a week vacation in Austria, a long weekend in the Netherlands and a $€ 100$ cheque. Participants were told that the more questionnaires they completed, the higher would be their chance of winning.

Employees who were interested to take part could fill in an online questionnaire in which inclusion criteria were checked: active command of Dutch, at least $24 \mathrm{~h}$ paid work a week (as work should constitute a substantial part of participants' lives), internet and e-mail access at home, no objections to being called during vacation, and a vacation period of at least 2 weeks between June 15th and August 22nd 2010.

Of initially 65 participants who met these inclusion criteria, 58 decided to take part in the study. During the study, four participants no longer wanted to take part, because of personal reasons. This resulted in a general response rate of $83 \%(N=54)$. Time point completion rates were high and varied between $83 \%$ (Inter 4) and $100 \%$ (general questionnaire).

Mean age of the participants was 42.5 years $(\mathrm{SD}=10.6)$ and half of them were women $(N=27)$. Of the sample, $53 \%$ had a college or university degree, $33 \%$ were medium 
educated (senior general secondary and university preparation education), and $13 \%$ were lower educated (lower secondary or junior secondary education). About a third (28\%) were technicians and associate professionals (e.g., nurse, webmaster), $22 \%$ were managers or senior officers, $22 \%$ were professionals (e.g., doctor or consultant), $11 \%$ worked as clerical support workers, $11 \%$ as service and sales workers, and the remaining $6 \%$ had other occupations. A minority (11\%) worked freelance or was self-employed. On average, the participants worked $35.2 \mathrm{~h}$ per week $(\mathrm{SD}=7.2)$ with a minimum of $24 \mathrm{~h}$ and a maximum of $55 \mathrm{~h}$ a week.

\subsection{Measures}

\subsubsection{Health and Well-Being}

The comprehensive construct of $\mathrm{H} \& \mathrm{~W}$ was composed of six indicators: health status, fatigue, satisfaction, mood, tension and energy level. All indicators were assessed with single-item measures. The basic Dutch grade notation system ranging from 1 (extremely low/negative) to 10 (extremely high/positive) was adopted and the first and the last grade were anchored. Health status was measured by the item: "How was your health today?" $(1=$ "very unhealthy", $10=$ "very healthy"). Fatigue was assessed with the item: "How tired did you feel today?" ( $1=$ "not tired at all", $10=$ "very tired"). We measured satisfaction with the item: "How satisfied do you feel about this day?" ( 1 = "very dissatisfied", 10 = "very satisfied"). Mood was assessed with the question: "How was your mood today?" ( 1 = "very bad", $10=$ "very good"). Tension was measured with the question: "How tense did you feel today?" (1 = "very calm", $10=$ "very tense"). Finally, energy level was assessed with the question: "How energetic did you feel today?" $(1=$ "not energetic at all", $10=$ "very energetic"). To find out if there was one underlying construct for the six $\mathrm{H} \& \mathrm{~W}$ indicators, an exploratory factor analysis was performed on every single measurement occasion. These factor analyses resulted in one-factor solutions with Eigenvalues greater than 1 and factor loadings ranging from 0.46 to 0.91 .

\subsubsection{Vacation Activities}

Participants were asked to estimate the time they had engaged in different types of vacation activities on the first workday after vacation in order to keep telephone surveys during vacation as brief as possible. They were asked retrospectively which percentage of their vacation time they had spent on (1) physical, (2) social and (3) passive activities during their vacation. For all types of activities, four examples were given to help participants categorize their vacation activities.

\subsubsection{Work-Related Activities}

Previous research suggests that work-related activities during vacation are not very prevalent, which makes it difficult to report the time spent on working in percentages (De Bloom et al. in press). Therefore, we tried to get a more detailed picture of time engaged in working by asking participants at Inter 1, 2, 3, and Inter 4 to indicate the number of hours they had devoted to work-related activities during the preceding 4 days. Moreover, we asked participants what they actually did by means of an open question. 


\subsubsection{Pleasure from Activities}

Participants were asked to rate the pleasure they derived from their vacation activities during the previous 4 days ( $1=$ "very unpleasant", $10=$ "very pleasant").

\subsubsection{Recovery Experiences}

To measure relaxation, psychological detachment and control over leisure time during vacation, we applied scales of the Recovery Experience Questionnaire (Sonnentag and Fritz 2007). Each construct was measured with three items that were adapted to the vacation context. Participants could respond on a 5-point Likert scale, ranging from " $1=$ strongly disagree" to " $5=$ strongly agree". An example item for psychological detachment from work is: "During this vacation, I don't think about work at all". Relaxation was assessed with items like: "During this vacation, I use the time to relax", and an example item for control is: "During this vacation, I determine for myself how I will spend my time".

\subsubsection{Savoring}

The four questions regarding savoring during vacation were adapted from the "Savoring Beliefs Inventory" (Bryant 2003) and also adjusted to the vacation context. Example-items are: "I don't enjoy things as much as I should during this vacation" and "I feel fully able to appreciate good things during this vacation" $(1=$ "completely disagree", $7=$ "completely agree"). An exploratory factor analysis resulted in a one-factor solution with an Eigenvalue greater than 1 and factor loadings ranging from 0.83 to 0.92 .

\subsubsection{Sleep}

Regarding sleep, we measured sleep duration (quantity) as well as sleep quality, because they are related but not identical constructs (Pilcher et al. 1997). In order to assess sleep quantity during vacation, we asked the participants to indicate how many hours they slept on average during the previous four nights. To assess sleep quality we asked the participants: "How did you generally sleep during the previous four nights?" $(1=$ "very poorly", $10=$ "very well").

\subsubsection{Statistical Analyses}

First of all, we calculated means, standard deviations and zero-order correlations for all study variables (see Table 2).

\subsubsection{Research Question 1}

The development in $\mathrm{H} \& \mathrm{~W}$ during and after long vacations was tested in a repeated measures analysis. To retain as many cases as possible in this general analysis (as every participant with a single missing value on any occasion would be discarded from analysis), the four occasions during vacation (i.e. Inter 1 , Inter 2 , Inter 3 , Inter $4=$ Inter) were averaged as well as the two occasions in the first week after vacation (Post 1.1, Post $1.2=$ Post 1$)$. We applied an analysis of variance (ANOVA) with repeated measures on the six occasions before, during and after vacation (Pre, Inter, Post 1, Post 2, Post 3, 


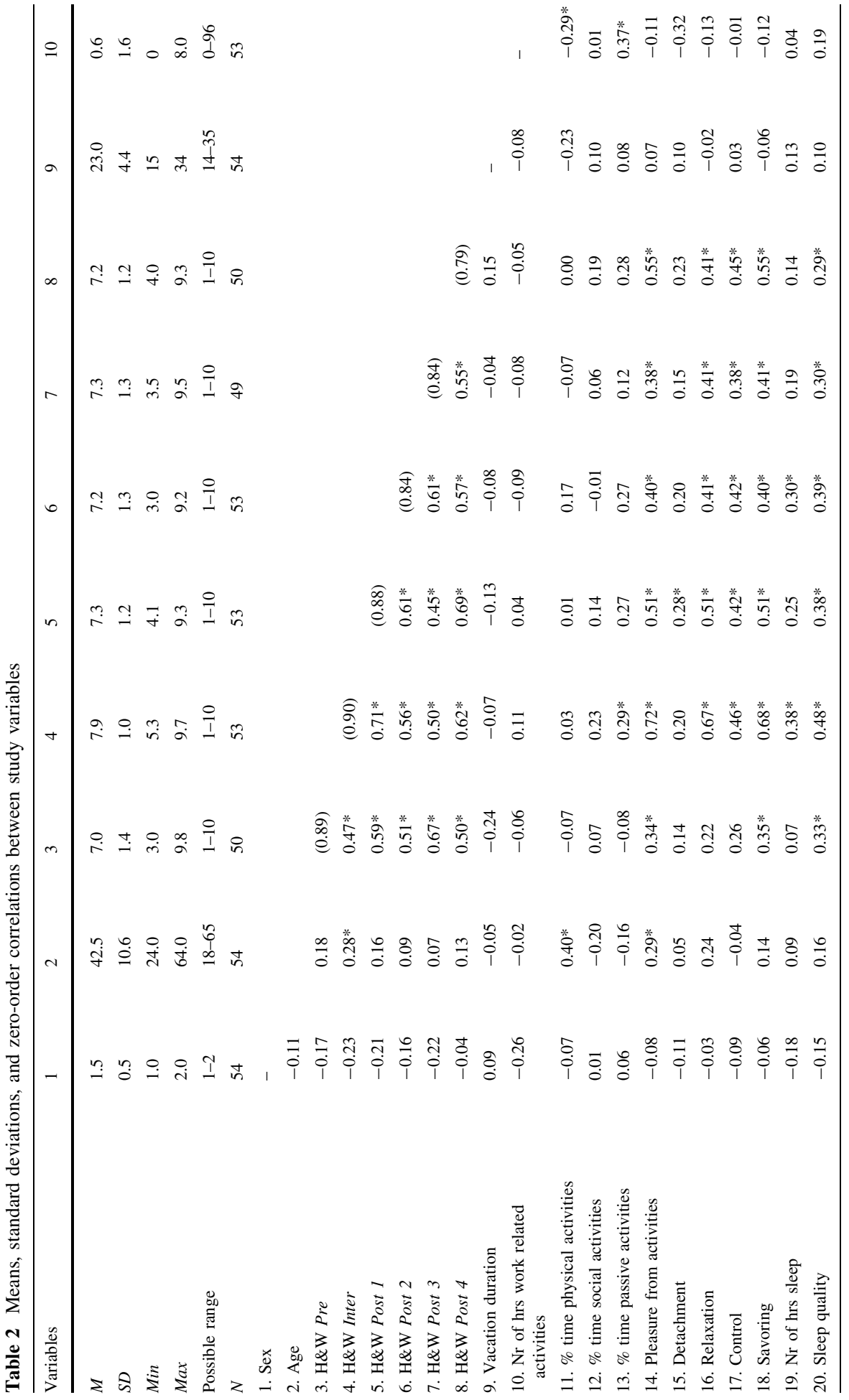




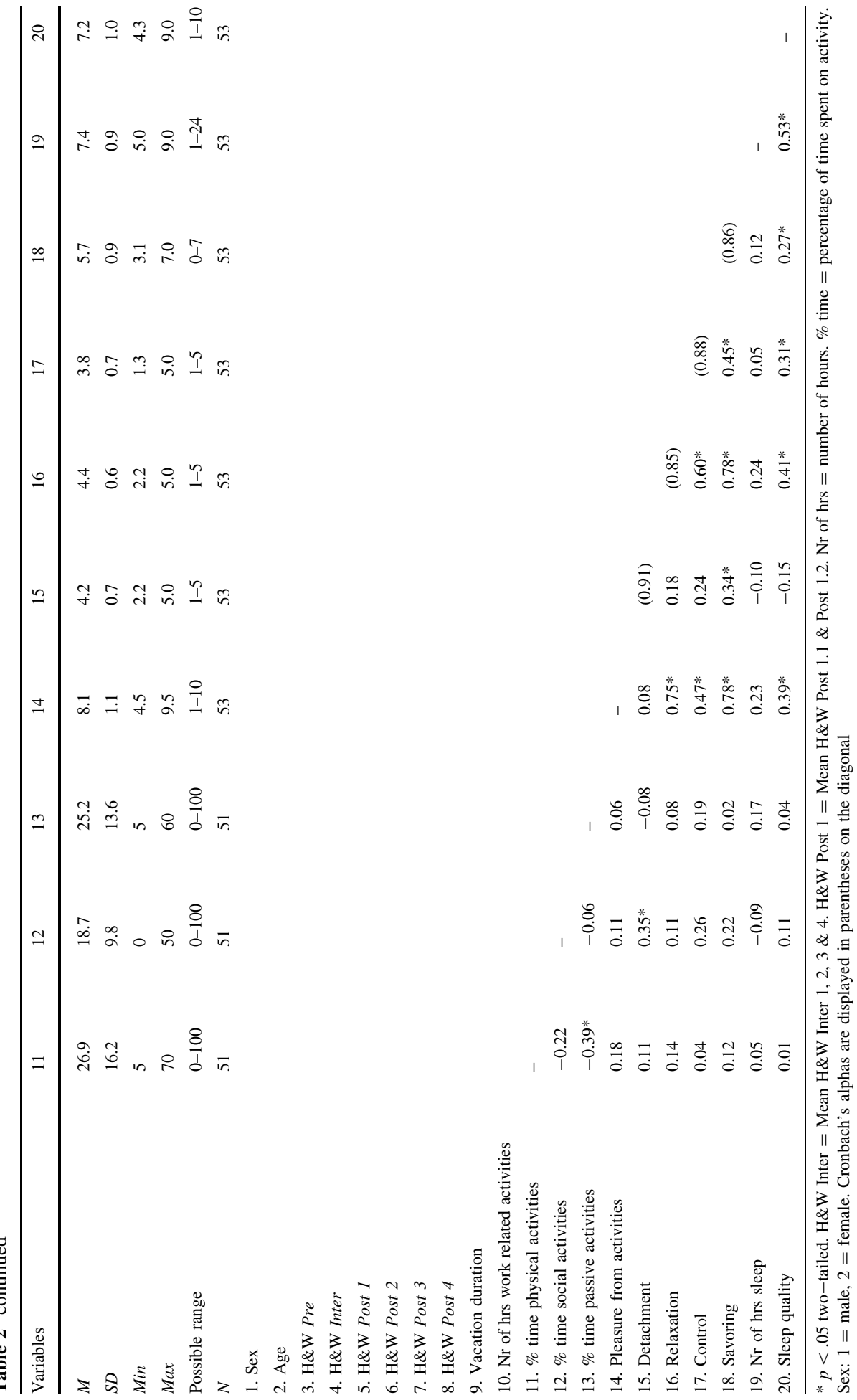


Post 4) and Least Significant Difference (LSD) post hoc tests to compare meaningful measurement occasions following previous definitions of vacation effects and vacation after-effects (De Bloom et al. 2009). Vacation effects on $\mathrm{H} \& \mathrm{~W}$ are present if $\mathrm{H} \& \mathrm{~W}$ before vacation differ significantly from $\mathrm{H} \& \mathrm{~W}$ during vacation (Pre versus Inter). Vacation aftereffects represent a significant difference between $\mathrm{H} \& \mathrm{~W}$ before compared to $\mathrm{H} \& \mathrm{~W}$ in the weeks after vacation (Pre versus Post 1, Post 2, Post 3, and Post 4 respectively). We also calculated Cohen $d$ 's for paired observations as an effect size for significant differences between these occasions (Cohen 1988) and we distinguish small (0-0.5), medium (0.5-0.8) and large $(>0.8)$ effects.

To study the development in $\mathrm{H} \& \mathrm{~W}$ in greater detail and to test whether $\mathrm{H} \& \mathrm{~W}$ levels differed on the occasions during vacation, we conducted a second repeated measures ANOVA on all 10 measurement occasions across vacation ( $\mathrm{H} \& \mathrm{~W}$ means of this analysis are displayed in Fig. 1). Please bear in mind that the missing cases on each of our 10 occasions (response rate $>82 \%$ on all occasions) reduce the total number of cases in this ANOVA, resulting in $31 \%$ reduced sample size $(\mathrm{N}=54-17=37)$.

In order to verify whether results from this second analysis also hold for the full sample, we additionally analysed the data with paired samples t-tests in which we merely compared two occasions at a time (and therefore retained a greater sample). Moreover, we conducted Little's MCAR test (Little 1988) to examine whether missing values were distributed randomly. Results of the $t$ tests strongly resembled the results of the ANOVA's and Little's MCAR test was non-significant $\left(\chi^{2}(103, \mathrm{~N}=54)=113.61, p=.22\right)$. Therefore, we are confident that results in this smaller subsample also hold for the entire sample.

To examine the relation between vacation duration and $\mathrm{H} \& \mathrm{~W}$ changes during and after vacation, we calculated partial correlations between vacation length (in days) and $\mathrm{H} \& \mathrm{~W}$ Inter, Post 1, Post 2, Post 3 and Post 4, controlling for H\&W Pre (as we were interested in the change from Pre to Inter and to Post), sex and age (see Table 3).

\subsubsection{Research Question 2 and 3}

To investigate the relationship between vacation activities, experiences and sleep on the one hand and $\mathrm{H} \& \mathrm{~W}$ changes during and after vacation on the other hand, we calculated partial correlations (Table 3). We again controlled for sex, age and pre-vacation H\&W (as we were interested in the change in $\mathrm{H} \& \mathrm{~W}$ ). To obtain a more robust measure of activities and experiences for the whole vacation period, we averaged the four vacation scores of engagement in work-related activities, vacation experiences (i.e. pleasure, detachment, relaxation, control and savoring, respectively) and sleep (i.e. quantity and quality).

\section{Results}

\subsection{Development of H\&W During and After Long Vacations (Research Question 1)}

The development of $\mathrm{H} \& \mathrm{~W}$ in relation to baseline $\mathrm{H} \& \mathrm{~W}$ before vacation (Pre) is displayed in Table 2 and Fig. 1.

Multivariate analysis of variance on the six occasions before, during and after vacation (Pre, Inter, Post 1, Post 2, Post 3, Post 4) revealed a main effect across time (F (5, $39)=7.34, p<.001)$, meaning that $\mathrm{H} \& \mathrm{~W}$ levels varied across the six measurement occasions. Post hoc LSD tests further demonstrated that H\&W during vacation was significantly higher than $\mathrm{H} \& \mathrm{~W}$ before and after vacation. In terms of effect sizes, the average 


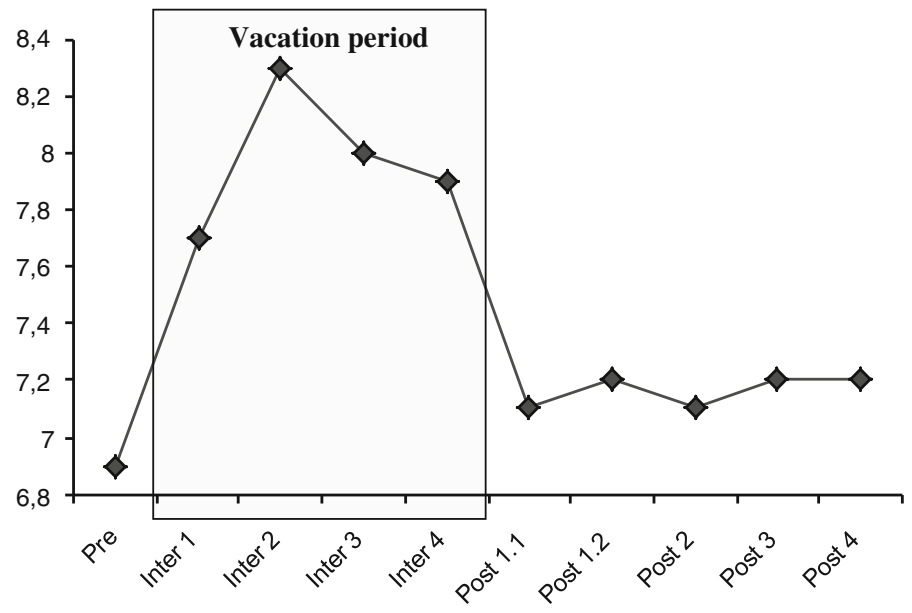

Fig. 1 Mean levels of H\&W (1-10) before, during and after vacation

change in $\mathrm{H} \& \mathrm{~W}$ from Pre to Inter represented a medium effect size $(d=0.73)$. Regarding vacation after-effects, none of the differences between Pre (before vacation) and Post (after vacation) was significant (all $p$ 's $>.20$ ). So, within the first week of work resumption, $\mathrm{H} \& \mathrm{~W}$ levels were comparable to those before vacation.

Regarding the detailed development across all 10 occasions, a second repeated measures ANOVA once more showed a main effect across time $(F(9,28)=4.53, p<.001)$. Post hoc LSD tests confirmed the results above: H\&W on each single measurement occasion during vacation was significantly higher than $\mathrm{H} \& \mathrm{~W}$ on each occasion before and after vacation. Moreover, baseline H\&W (Pre) did not differ from any occasion after vacation, meaning that positive vacation effects have faded out on the first work day within the first week of work resumption.

Regarding the development of $\mathrm{H} \& \mathrm{~W}$ during vacation, LSD tests showed that $\mathrm{H} \& \mathrm{~W}$ on Inter 1 already differed from baseline, which means that $\mathrm{H} \& \mathrm{~W}$ increased during the first four vacation days $(d=0.39)$. Between the 4 th (Inter 1$)$ and the 8 th (Inter 2$)$ vacation day, $\mathrm{H} \& \mathrm{~W}$ further increased significantly ( $d$ Inter 1 vs. Inter $2=0.48$, Pre vs. Inter $2=0.79$ ). All other pairwise comparisons during vacation (Inter 1 vs. Inter 3; 1 vs. 4; 2 vs. 3; Inter 2 vs. 4 ; Inter 3 vs. 4 ) were non-significant.

In sum, H\&W levels rapidly improved during vacation and appeared to peak on the 8th day of vacation. In the first week of work resumption, $\mathrm{H} \& \mathrm{~W}$ has decreased and resembled baseline levels of $\mathrm{H} \& \mathrm{~W}$ before vacation.

\subsection{Vacation Duration (Related to Research Question 1)}

Vacation duration ranged from 15 to 34 days $(\mathrm{SD}=4.4)$, with an average of 23 days. A quarter of the sample ( $26 \%$ ) was on vacation for less than 22 days, $44 \%$ for 22 to 24 days and $30 \%$ were on holiday for more than 24 days. Table 3 demonstrates that vacation duration was not associated with changes in $\mathrm{H} \& \mathrm{~W}$ during and after vacation, with the exception of the fourth week after work resumption: changes in $\mathrm{H} \& \mathrm{~W} 4$ weeks after vacation were positively related to vacation duration $(r=0.32$, Table 3$)$. In short, the development in $\mathrm{H} \& \mathrm{~W}$ during and shortly after vacation was independent of vacation duration. 
Table 3 Partial correlations of health and well-being during vacation (Inter) and after vacation (Post 1, Post 2 , Post 3, Post 4) with vacation duration, activities, experiences and sleep controlled for health and wellbeing before vacation (Pre), sex and age

\begin{tabular}{|c|c|c|c|c|c|}
\hline Variable & $\begin{array}{l}\mathrm{H} \& \mathrm{~W} \text { Inter } \\
\text { During } \\
\text { vacation }\end{array}$ & $\begin{array}{l}\text { H\&W Post } 1 \\
1 \text { st week after } \\
\text { vacation }\end{array}$ & $\begin{array}{l}\text { H\&W Post } 2 \\
\text { 2nd week after } \\
\text { vacation }\end{array}$ & $\begin{array}{l}\mathrm{H} \& \mathrm{~W} \text { Post } 3 \\
3 r d \text { week after } \\
\text { vacation }\end{array}$ & $\begin{array}{l}\mathrm{H} \& \mathrm{~W} \text { Post } 4 \\
\text { 4th week after } \\
\text { vacation }\end{array}$ \\
\hline Vacation duration & 0.07 & 0.02 & 0.06 & 0.17 & $0.32 *$ \\
\hline \multicolumn{6}{|l|}{ Activities } \\
\hline $\begin{array}{l}\mathrm{Nr} \text { of hrs } \\
\quad \text { work-related } \\
\text { activities }\end{array}$ & 0.12 & 0.06 & -0.10 & -0.10 & -0.00 \\
\hline $\begin{array}{l}\% \text { time } \\
\text { physical } \\
\text { activities }\end{array}$ & -0.03 & 0.04 & $0.27 *$ & -0.02 & 0.04 \\
\hline $\begin{array}{l}\% \text { time } \\
\quad \text { social } \\
\text { activities }\end{array}$ & $0.29 *$ & 0.15 & -0.05 & 0.01 & 0.19 \\
\hline $\begin{array}{l}\% \text { time } \\
\text { passive } \\
\text { activities }\end{array}$ & $0.43 *$ & $0.41^{*}$ & $0.38 *$ & 0.23 & $0.38^{*}$ \\
\hline \multicolumn{6}{|l|}{ Experiences } \\
\hline $\begin{array}{l}\text { Pleasure } \\
\text { from } \\
\text { activities }\end{array}$ & $0.67 *$ & $0.41^{*}$ & $0.29 *$ & 0.25 & $0.47 *$ \\
\hline Detachment & 0.14 & 0.24 & 0.15 & 0.07 & 0.19 \\
\hline Relaxation & $0.65 *$ & $0.49 *$ & $0.37 *$ & $0.40^{*}$ & $0.35 *$ \\
\hline Control & $0.43^{*}$ & $0.34 *$ & $0.35^{*}$ & $0.28 *$ & $0.40 *$ \\
\hline Savoring & $0.63 *$ & $0.40 *$ & $0.28 *$ & $0.27 *$ & $0.46^{*}$ \\
\hline \multicolumn{6}{|l|}{ Sleep } \\
\hline $\begin{array}{l}\text { Sleep } \\
\quad \text { duration }\end{array}$ & $0.38 *$ & 0.24 & $0.30^{*}$ & 0.18 & 0.14 \\
\hline Sleep quality & $0.38 *$ & 0.23 & $0.27 *$ & 0.11 & 0.16 \\
\hline
\end{tabular}

$* p<.05$ one-tailed, $\mathrm{Nr}$ of hrs $=$ number of hours, $\%$ time $=$ percentage of time spent on activity

\subsection{Vacation Activities (Research Question 2)}

For each activity and experience, we will first report the descriptives (Table 2). In order to answer research question 2, we will then focus on the partial correlations between vacation activities and experiences on the one hand, and changes in $\mathrm{H} \& \mathrm{~W}$ from Pre to Inter and to Post on the other hand (Table 3).

\subsubsection{Work-Related Activities}

Spending time on work-related activities was reported by 15 vacationers (28\%). Mean working time over the course of 4 days was $0.6 \mathrm{~h}$ for all vacationers and $2.2 \mathrm{~h}$ for working vacationers (that is about 33 min per day). Maximum working time was $8 \mathrm{~h}$ within 4 days. Of those who engaged in work-related activities during vacation, $47 \%$ emailed, $53 \%$ made phone calls and $53 \%$ reported other activities (such as updating calendars, fixing a 
malfunction or organizing a dinner for a colleague). Time spent on work-related activities during vacation was not linked to changes in $\mathrm{H} \& \mathrm{~W}$ during and after vacation (see Table 3 ).

\subsubsection{Physical Activities}

On average, vacationers spent $27 \%$ of their vacation on physical activities. Time spent on physical activities during vacation was generally not associated with changes in $\mathrm{H} \& \mathrm{~W}$ during and after vacation, with the exception of $\mathrm{H} \& \mathrm{~W}$ on Post 2 ( $r=0.27$; Table 3$)$.

\subsubsection{Social Activities}

Vacationers spent $19 \%$ of their vacation time on social activities. Partial correlations revealed that more time spent on social activities was related to improvements in $\mathrm{H} \& \mathrm{~W}$ during vacation $(r=0.29$; Table 3$)$. After vacation, time spent on social activities was unrelated to $\mathrm{H} \& \mathrm{~W}$ changes.

\subsubsection{Passive Activities}

On average, vacationers spent a quarter of their vacation time on passive activities. Time spent on passive activities was substantially related to increases in $\mathrm{H} \& \mathrm{~W}$ during $(r=0.43)$ and after vacation $(r=0.41,0.38,0.23$ and 0.38 ; Table 3$)$ with the exception of H\&W Post 3.

\subsection{Vacation Experiences (Research Question 2)}

\subsubsection{Pleasure from Activities}

Most participants derived pleasure from their vacation activities, reporting 8.1 points on a 10 -point scale. Pleasure from activities was substantially related to improvements in $\mathrm{H} \& \mathrm{~W}$ during $(r=0.67)$ and after vacation $(r=0.41,0.29,0.25$ and 0.47 ; Table 3$)$ with the exception of H\&W Post 3.

\subsubsection{Detachment}

Vacationers were generally well able to detach psychologically from work, as evidenced by a mean score of 4.2 points on a 5-point scale. Detachment was not related to changes in $\mathrm{H} \& \mathrm{~W}$ during vacation and after work resumption (see Table 3).

\subsubsection{Relaxation}

The mean level of relaxation during vacation was high: 4.4 on a 5-point scale. Partial correlations showed that relaxation was clearly linked to increases in $\mathrm{H} \& \mathrm{~W}$ during $(r=0.65)$ and after vacation $(r=0.49,0.37,0.40$ and 0.35 ; Table 3$)$.

\subsubsection{Control}

On average, participants scored 3.8 on a 5-point scale. Control over how to spend vacation time was positively related to improvements in $\mathrm{H} \& \mathrm{~W}$ on all measurement occasions, that is during $(r=0.43)$ and after vacation $(r=0.34,0.35,0.28$ and 0.40 ; Table 3$)$. 


\subsubsection{Savoring}

Participants reported high levels of savoring: 5.7 on a 7-point scale. The more people savored during vacation, the more their $\mathrm{H} \& \mathrm{~W}$ increased during $(r=0.63)$ and after vacation $(r=0.40,0.28,0.27$ and 0.46 ; Table 3$)$.

\subsection{Sleep (Research Question 3)}

\subsubsection{Sleep Duration}

On average, participants reported to sleep $7.4 \mathrm{~h}$ per night during vacation (before vacation, mean sleep time was $6.7 \mathrm{~h}$, which is significantly less than during vacation, $\mathrm{t}(48)=-4.6)$. Sleep duration was related to increases in $\mathrm{H} \& \mathrm{~W}$ during $(r=0.38)$ and to a lesser degree after vacation $(r=0.24,0.30,0.18$ and 0.14 ; Table 3$)$.

\subsubsection{Sleep Quality}

Vacationers reported high levels of sleep quality: 7.2 points on a 10-point scale. Sleep quality was also associated with positive changes in $\mathrm{H} \& \mathrm{~W}$ during $(r=0.38)$ and to a lesser degree after vacation $(r=0.23,0.27,0.11$ and 0.16 ; Table 3$)$.

\section{Discussion}

\subsection{Development of H\&W During and After Long Vacations (Research Question 1)}

The first aim of this longitudinal field study on long summer vacations was to investigate vacation (after-) effects on employee $\mathrm{H} \& \mathrm{~W}$. We found that $\mathrm{H} \& \mathrm{~W}$ increase during long vacations (effect size Cohen $d$ for the vacation effect was 0.73 ). The vacation effect in this study is comparable to the vacation effect reported in studies which measured H\&W during winter sports (De Bloom et al. 2011) and during short vacations (De Bloom et al. 2011) and indicates that a holiday serves as a respite which enables employees to recover from work.

Concerning the development of H\&W during vacation, our results showed that $\mathrm{H} \& \mathrm{~W}$ rapidly increase after the start of the holiday and seemed to peak on the eighth vacation day. This finding corroborates earlier research which suggests that it takes some time to wind down after a stressful work period and acclimatize to vacation (Nawijn 2010; Van Heck and Vingerhoets 2007). More research in larger samples is necessary to further unravel the development in $\mathrm{H} \& \mathrm{~W}$ and its determinants during vacation.

On the first day of work resumption, positive vacation effects on $\mathrm{H} \& \mathrm{~W}$ have already entirely faded out. This finding is consistent with earlier studies in which mostly no or only small increases in well-being after vacation were found (e.g. Gilbert and Abdullah 2004; Lounsbury and Hoopes 1986; Westman and Etzion 2001). However, inspections of the means after vacation suggest that we might have found positive after-effects if we had used a larger sample size and consequently would have had more power. More research on this issue is therefore needed.

The present study makes a contribution to understanding long term recovery: frequent respites might be more important to preserve well-being than the duration of one single 
recovery episode. Our results regarding the rapid fade-out of a positive vacation effect also accentuate the methodological importance of on-vacation measures in vacation research.

\subsection{The Role of Vacation Activities and Experiences (Research Question 2)}

The second aim of this study was to examine the role of different vacation activities and experiences in the strength and persistence of vacation effects. Concerning vacation activities, merely engagement in passive and social activities was linked to positive changes in $\mathrm{H} \& \mathrm{~W}$ during vacation, whereby only the positive effects of passive activities persisted after vacation. In combination with the fact that (1) most subjective experiences under study were quite strongly associated with improvements in $\mathrm{H} \& \mathrm{~W}$ during and after vacation and (2) previous research on the recovery potential of leisure activities showed mixed results, our results support the idea that vacation experiences may be especially important for vacation (after) effects. However, we need to keep in mind that engagement in certain vacation activities often constitutes the basis for experiences (e.g. pleasure), meaning that experiences and activities are by definition closely related.

A notable finding is the positive relation between engagement in passive activities and improvements in $\mathrm{H} \& \mathrm{~W}$, as earlier studies on recovery revealed no or even negative relations between passive activities and well-being (De Bloom et al. 2011; Rook and Zijlstra 2006). However, summer vacations are mostly intended to be relaxing vacations. For many summer vacationers, relaxing and simply "doing nothing" is therefore indicative of a successful vacation: vacationers could do what they came for. Consequently, our findings seem to underscore the importance of autonomy. If vacationers are able to decide how to spend their leisure time, their $\mathrm{H} \& \mathrm{~W}$ increase.

Regarding vacation experiences, relaxation, pleasure derived from activities and savoring were most strongly and consistently associated with improvements in $\mathrm{H} \& \mathrm{~W}$ during and after vacation. However, relaxing is generally associated with few social demands, low physical and intellectual activation and high positive affect (Stone et al. 1995; Tinsley and Eldredge 1995). Therefore, relaxation may also be seen as an outcome of vacation rather than a determinant of positive $\mathrm{H} \& \mathrm{~W}$ changes during vacation. So, the causal direction of the relation between $\mathrm{H} \& \mathrm{~W}$ and relaxation is not entirely clear. Pleasure derived from leisure activities was shown to be important in other studies on recovery as well, which emphasizes the benefit of self-determined behavior (De Bloom et al. in press; Ryan et al. 2010; Van Hooff et al. 2011). It may not be most crucial which specific activity vacationers pursue during vacation, as long as they perceive engaging in this activity as pleasant. This reasoning is also in line with our finding that control or the freedom to decide which activity to engage in is strongly associated with improvements in well-being across a vacation period.

The degree to which vacationers were able to savor positive vacation experiences was also strongly linked to improvements in $\mathrm{H} \& \mathrm{~W}$ during and after vacation. Despite the fact that people may differ in the extent to which they tend or are able to savor positive experiences, research suggests that strategies to savor can be learned (Bryant et al. 2005; Bryant and Veroff 2007), which may probably increase the benefits of vacation as well.

Whilst psychological detachment from work was associated with well-being in earlier vacation studies (De Bloom et al. in press; Fritz and Sonnentag 2006), we found no significant associations with improvements in $\mathrm{H} \& \mathrm{~W}$ during and after vacation. A possible explanation could be the high mean level of detachment, which possibly led to a restriction of range. 


\subsection{The Role of Sleep (Research Question 3)}

Another aim of this study was to examine the relationship between sleep and changes in $\mathrm{H} \& \mathrm{~W}$ across a vacation period. Both sleep quantity and quality were related to positive $\mathrm{H} \& \mathrm{~W}$ changes. The longer and the better vacationers slept, the more their $\mathrm{H} \& \mathrm{~W}$ increased during vacation and 2 weeks thereafter. Yet, the causal direction in these relationships remains unclear. It could be that a holiday enables vacationers to get a "good nights' sleep" which in turn improves well-being. But it may also be that vacationing improves well-being which in turn leads to higher sleep quality and quantity.

\subsection{Limitations and Strengths}

First and foremost, the small sample size, the accompanying limited statistical power and the relatively high level of education of the participants may limit the external validity of our study. In a similar vein, we should keep in mind that long vacations are mostly reserved for Europeans. Nevertheless, research on the effects of long vacations enables us to better understand underlying long term recovery processes and we have no reason to believe that these processes would proceed in a different way in different samples or countries.

Secondly, the diversity in vacation length gave us the opportunity to study the role of vacation duration. However, this variation makes comparisons of $\mathrm{H} \& \mathrm{~W}$ towards the end of the holiday complicated. For example, for somebody who returned home after 18 days of vacation, $\mathrm{H} \& \mathrm{~W}$ on the 16th vacation day might have been different (due to leaving already a couple of days later) than for somebody who stayed 25 days (and for whom a long respite still lies ahead). For the few vacationers who went on very long vacations (e.g. seven vacationers went on a holiday for more than 30 days), information on $\mathrm{H} \& \mathrm{~W}$ during the second half of their vacation is not available. Still, our analyses do not propose any structural differences between vacationers with varying vacation lengths during and after vacation. It is therefore unlikely that $\mathrm{H} \& \mathrm{~W}$ would suddenly peak in the second half of a very long vacation.

Thirdly, the retrospective assessment of vacation activities (social, physical and passive) may be biased, because vacationers may not be able to estimate the exact percentages of time they devoted to certain activities. In this respect, on-vacation measures would have been more precise. However, we preferred a one-shot measurement, because it restricted the effort and time demanded from the vacationers during their holiday and prevented nonresponse (see Newman 2009). Moreover, an estimation of the percentage spent on certain activities during the whole vacation may render a better, more general picture than the recordings of activities of three or four specific days in a long vacation period of 23 days.

Fourthly, not all measures included in this study were extensively validated measures (although 'recovery experiences' as well as 'savoring' were adapted from validated instruments; Bryant 2003; Sonnentag and Fritz 2007). Because of the study design ('diary design', repeated measures) and setting (e.g. across vacation), we employed single-item measures (i.e. report marks) to measure $\mathrm{H} \& \mathrm{~W}$ as well as pleasure and sleep quality. There are good arguments in favor of this choice. First, participants generally value the directness of single-item measures and the lack of repeated comparable items (Elo et al. 2003; Van Hooff et al. 2007b). Minimizing effort and maximizing user-friendliness for the participants in a time-consuming research as ours are vital ingredients to reduce non-response. Second, single-item measures are often good equivalents of well-validated multiple item measures. For instance, Van Hooff et al. (2007b) provided convergent and discriminant 
validity evidence of a single item measure of fatigue that was by no means inferior to a well-validated six-item fatigue scale.

Concerning strengths, especially our telephone interviews which enable participantfriendly and reliable measurements during vacation deserve to be mentioned. In addition, our repeated measures after vacation made it possible to study fade-out processes in detail. Moreover, our baseline measurement of $\mathrm{H} \& \mathrm{~W}$ may be more representative for general $\mathrm{H} \& \mathrm{~W}$ and therefore more valid than baseline measurements immediately before vacation. Last but not least, we succeeded in keeping non-response rates very low by taking actions as suggested in Newman's theoretical model of survey response (Newman 2009), including for example tailor-made, polite invitations, follow-up reminders, valuable lottery prices, the use of attractive new media (SMS, personalized emails) and short questionnaires.

\subsection{Practical Implications}

This research has, like several studies before, shown that employee' well-being improves during but not after vacation. Regarding vacation duration, findings of individual studies may have their weaknesses, but the general preponderance of studies, including our own, indicates that vacation duration is hardly important for the strength and persistence of vacation effects. So, if vacationing 'recharges the batteries' and replenishes lost resources, why does this 'reload' not persist after work resumption? Or stated differently: why should we spend time and money on a vacation which seems to have fleeting effects? First and foremost, research suggests that not taking annual vacations is associated with illness or even premature death (Gump and Matthews 2000). Secondly, it is possible that vacation research so far has not embraced all crucial aspects of $\mathrm{H} \& \mathrm{~W}$ that may be influenced by a holiday. Think for instance of psycho-physiological health (e.g., cardiovascular parameters), performance and long term workability, the ability to get another perspective on life, creativity and relationship quality. Vacations may also prevent demoralization in the workforce and create psychological resilience to buffer future stress. Thirdly, it could also be that general $\mathrm{H} \& \mathrm{~W}$ return to baseline levels rapidly after vacation, but that vacation memories have the power to increase well-being again, but only temporarily. Asking why we should keep going on vacations is therefore comparable to asking why we should go to sleep considering the fact that we get tired again. A period of effort investment at work should necessarily be alternated with periods of recovery in order to remain healthy in the long run. Therefore, instead of skipping vacations or taking only one long vacation in years, it seems much more reasonable to schedule several shorter vacations across a work year in order to maintain high levels of H\&W (see also Etzion 2003).

Our results also indicate that vacation experiences (often derived from the activities vacationers engage in) may be more important for $\mathrm{H} \& \mathrm{~W}$ improvements than vacation activities per se. It is important for workers to derive pleasure from their activities. This can probably be achieved by freely deciding which activity to pursue during vacation and this form of control also seem to be directly linked to increases in H\&W during vacation. Recent research suggests that it may be possible to teach individuals how to recover successfully by promoting recovery experiences like control and relaxation (Hahn et al. 2011).

Concerning our results about sleep, it would be useful to pay special attention to favorable sleeping conditions during vacation. About $8 \mathrm{~h}$ sleep per night and sleeping in a comfortable environment during vacation (e.g. in a dark, quiet, well-tempered room) seem to enhance well-being during and even after vacation. 


\subsection{Future Research}

First, studies on the effect of not taking holidays for a longer time are highly needed. A study by Gump and Matthews (2000) demonstrated in a longitudinal study covering a 9 year period that not taking annual vacations was associated with a higher risk of mortality, in particular attributed to cardiovascular diseases. Similar longitudinal studies on healthy men and women could help to develop vacation schemes for optimal recovery across a work year. Second, other determinants of vacation (after-) effects deserve a place on the agenda for future research as well. Worrying about work during vacation, person characteristics (e.g. workaholism, personality traits), type of job or vacation location (especially at home vs. abroad) may be possible candidates.

Third, methodologically, vacation studies would benefit from data triangulation in the form of additional physiological measures (e.g. blood pressure, heart rate, cortisol), and supervisor and partner ratings.

Fourth, it is possible that vacations promote health over the life span and have longer lasting effects on aspects, which we have not yet assessed. Future studies could for example focus on vacation effects on long term workability and performance, the ability to put life into perspective, creativity, relationship quality or psychological resilience.

Fifth, it would be interesting to study pre-vacation time. Some researchers argue that the time before vacation may be characterized by stress due to for instance high pre-vacation workload or travelling stress (DeFrank et al. 2000; Nawijn et al. 2011). This pre-vacation stress may even be higher in case of long vacations as these often need more cautious preparations. Last but not least, it would be desirable to develop, implement and evaluate interventions aimed at increasing and prolonging the positive effects of vacation.

Acknowledgments We thank Desiree Traanman, Jennifer Reinders, Stefan Bernritter and Mirjam Huijs for their help in collecting the data for this study. Moreover, we thank Pieter van Groenestijn and William Burk from the RTOG for helping digitalizing and analyzing the diaries and Lorraine Hagemeijer and Jennifer Reinders for analyzing parts of the data in order to write their bachelor/master theses.

Open Access This article is distributed under the terms of the Creative Commons Attribution License which permits any use, distribution, and reproduction in any medium, provided the original author(s) and the source are credited.

\section{References}

Akerstedt, T. (2006). Psychosocial stress and impaired sleep. Scandinavian Journal of Work, Environment \& Health, 32, 493-501.

Akerstedt, T., Nilsson, P. M., \& Kecklund, G. (2009). Sleep and recovery. In S. Sonnentag, P. L. Perrewe, \& D. C. Ganster (Eds.), Current perspectives on job-stress recovery research in occupational stress and well-being (Vol. 7, pp. 205-247). Bingley, UK: Emerald Group Publishing Unlimited.

Belkic, K. L., Landsbergis, P. A., Schnall, P. L., \& Baker, D. (2004). Is job strain a major source of cardiovascular disease? Scandinavian Journal of Work and Environmental Health, 30, 85-128.

Bryant, F. B. (2003). Savoring beliefs inventory (SBI): A scale for measuring beliefs about savouring. Journal of Mental Health, 12, 175-196.

Bryant, F. B., Smart, C. M., \& King, S. P. (2005). Using the past to enhance the present: boosting happiness through positive reminiscence. Journal of Happiness Studies, 6, 227-260.

Bryant, F. B., \& Veroff, J. (2007). Savoring: A new model of positive experience. Mahwah (NJ): Lawrence Erlbaum Associates.

Cohen, J. (1988). Statistical power analysis for the behavioral sciences. Hillsdale (NJ): Lawrence Erlbaum Associates. 
Dahlgren, A., Kecklund, G., \& Akerstedt, T. (2005). Different levels of work-related stress and the effects on sleep, fatigue and cortisol. Scandinavian Journal of Work and Environmental Health, 31, 277-285.

De Bloom, J., Geurts, S., \& Kompier, M. (2010). Vacation from work as prototypical recovery opportunity. Gedrag \& Organisatie, 23, 333-349.

De Bloom, J., Geurts, S. A. E., \& Kompier, M. A. J. (in press). Effects of short vacations, vacation activities and experiences on employee health and well-being. Stress and Health.

De Bloom, J., Geurts, S. A. E., Sonnentag, S., Taris, T., De Weerth, C., \& Kompier, M. A. J. (2011). How does a vacation from work affect employee health and well-being? Psychology \& Health, 26, $1606-1622$.

De Bloom, J., Kompier, M., Geurts, S., De Weerth, C., Taris, T., \& Sonnentag, S. (2009). Do we recover from vacation? Meta-analysis of vacation effects on health and well-being. Journal of Occupational Health, 51, 13-25.

DeFrank, R. S., Konopaske, R., \& Ivancevich, J. M. (2000). Executive travel stress: Perils of the road warrior. The Academy of Management Executive, 14, 58-71.

Eden, D. (2001). Vacations and other respites: Studying stress on and off the job. In C. Cooper \& I. T. Robertson (Eds.), Well-being in organizations (pp. 305-330). West Sussex (UK): Wiley.

Elo, A. L., Leppänen, A., \& Jahkola, A. (2003). Validity of a single-item measure of stress symptoms. Scandinavian Journal of Work, Environment \& Health, 29, 444-451.

Etzion, D. (2003). Annual vacation: duration of relief from job stressors and burnout. Anxiety, Stress, and Coping, 16, 213-226.

Etzion, D., Eden, D., \& Lapidot, Y. (1998). Relief from job stressors and burnout: reserve service as a respite. Journal of Applied Psychology, 8, 577-585.

Fredrickson, B. L. (2001). The role of positive emotions in positive psychology. The Broaden-and-Build Theory of positive emotions. American Psychologist, 56, 218-226.

Fritz, C., \& Sonnentag, S. (2005). Recovery, health, and job performance: effects of weekend experiences. Journal of Occupational Health Psychology, 10, 187-199.

Fritz, C., \& Sonnentag, S. (2006). Recovery, well-being, and performance-related outcomes: the role of workload and vacation experiences. Journal of Applied Psychology, 91, 936-945.

Fritz, C., Sonnentag, S., Spector, P., \& McInroe, J. A. (2010). The weekend matters: relationships between stress recovery and affective experiences. Journal of Organizational Behavior, 31, 1137-1162.

Geurts, S. A. E., \& Sonnentag, S. (2006). Recovery as an explanatory mechanism in the relation between acute stress reactions and chronic health impairment. Scandinavian Journal of Work, Environment \& Health, 32, 482-492.

Gilbert, D., \& Abdullah, J. (2002). A study of the impact of the expectation of a holiday on an individual's sense of well-being. Journal of Vacation Marketing, 8, 352-361.

Gilbert, D., \& Abdullah, J. (2004). Holidaytaking and the sense of well-being. Annals of Tourism Research, 31, 103-121.

Groeger, J. A., Zijlstra, F. R. H., \& Dijk, D. J. (2004). Sleep quantity, sleep difficulties and their perceived consequences in a representative sample of some 2000 British adults. Journal of Sleep Research, 13, 359-371.

Gump, B. B., \& Matthews, K. A. (2000). Are vacations good for your health? The 9-year mortality experience after the multiple risk factor intervention trial. Psychosomatic Medicine, 62, 608-612.

Hahn, V. C., Binnewies, C., Sonnentag, S., \& Mojza, E. J. (2011). Learning how to recover from job stress: effects of a recovery training program on recovery, recovery-related self-efficacy, and well-being. Journal of Occupational Health Psychology, 16, 202-216.

Hamilton, N. A., Nelson, C. A., Stevens, N., \& Kitzman, H. (2007). Sleep and physiological well-being. Social Indicators Research, 82, 147-163.

Härma, M. (2006). Workhours in relation to work stress, recovery and health. Scandinavian Journal of Environmental Health, 32, 502-514.

How long should a man's vacation be? (1910, July 31). The New York Times.

Kemp, S., Burt, C. D. B., \& Furneaux, L. (2008). A test of the peak-end rule with extended autobiographical events. Memory and Cognition, 36, 132-138.

Kühnel, J., \& Sonnentag, S. (2011). How long do you benefit from vacation? A closer look at the fade-out of vacation effects. Journal of Organizational Behavior, 32, 125-143.

Leger, D., Massuel, M. A., \& Metlaine, A. (2006). Professional correlates of insomnia. Sleep, 29, 171-178.

Little, R. J. A. (1988). A test of missing completely at random for multivariate data with missing values. Journal of the American Statistical Association, 83, 1198-1202.

Lounsbury, J. W., \& Hoopes, L. L. (1986). A vacation from work: changes in work and nonwork outcomes. Journal of Applied Psychology, 71, 392-401. 
Meijman, T. F., \& Mulder, G. (1998). Psychological aspects of workload. In P. J. D. Drenth, H. Thierry, C. J. de Wolff (Eds) Handbook of work and organizational psychology (2nd ed.). Work psychology (Vol. 2, pp. 5-33). Hove: Psychology Press.

Nawijn, J. (2010). The holiday happiness curve: A preliminary investigation into mood during a holiday abroad. International Journal of Tourism Research, 12, 281-290.

Nawijn, J., De Bloom, J., \& Geurts, S. (2011). Pre-vacation time: blessing or burden? Manuscript submitted for publication.

Nawijn, J., Marchand, M., Veenhoven, R., \& Vingerhoets, A. (2010). Vacationers happier, but most not happier after a holiday. Applied Research in Quality of Life, 5, 35-47.

Newman, D. A. (2009). Missing data techniques and low response rates The role of systematic nonresponse parameters. In C. E. Lance \& R. J. Vandenberg (Eds.), Statistical and methodological myths and urban legends. Doctrine, verity and fable in the organizational and social sciences. Hove, East Sussex: Routledge.

Nilsson, P. M., Nilsson, J. A., Hedblad, B., \& Berglund, G. (2001). Sleep disturbances in association with elevated pulse rate for the prediction of mortality: consequences of mental strain? Journal of Internal Medicine, 250, 521-529.

Pilcher, J. J., Ginter, D. R., \& Sadowsky, B. (1997). Sleep quality versus sleep quantity: relationships between sleep and measures of health, well-being and sleepiness in college students. Journal of Psychomatic Research, 42, 583-596.

Pressman, S. D., Matthews, K. A., Cohen, S., Martire, L. M., Scheier, A., Baum, A., et al. (2009). Association of enjoyable leisure activities with psychological and physical well-being. Psychosomatic Medicine, 71, 725-732.

Rook, J. W., \& Zijlstra, F. R. H. (2006). The contribution of various types of activities to recovery. European Journal of Work and Organizational Psychology, 15, 218-240.

Ryan, R. M., Bernstein, J. H., \& Brown, K. W. (2010). Weekends, work, and well-being: psychological need satisfactions and day of the week effects on mood, vitality, and physical symptoms. Journal of Social and Clinical Psychology, 29, 95-122.

Ryan, R. M., \& Deci, E. L. (2000). Self-Determination Theory and the facilitation of intrinsic motivation, social development, and well-being. American Psychologist, 55, 68-78.

Sonnentag, S., \& Fritz, C. (2007). The recovery experience questionnaire: development and validation of a measure for assessing recuperation and unwinding from work. Journal of Occupational Health Psychology, 12, 204-221.

Stone, A. A., Kennedy-Moore, E., \& Neale, J. M. (1995). Association between daily coping and end-of-day mood. Health Psychology, 14, 341-349.

Strauss-Blasche, G., Ekmekcioglu, C., \& Marktl, W. (2000). Does vacation enable recuperation? Changes in well-being associated with time away from work. Occupational Medicine, 50, 167-172.

Tinsley, H. E. A., \& Eldredge, B. D. (1995). Psychological benefits of leisure participation: a taxonomy of leisure activities based on their need-gratifying properties. Journal of Counseling Psychology, 42, 123-132.

Tucker, P., Dahlgren, A., Akerstedt, T., \& Waterhouse, J. (2008). The impact of free-time activities on sleep, recovery and well-being. Applied Ergonomics, 39, 653-662.

Van Heck, G. L., \& Vingerhoets, A. J. J. M. (2007). Leisure sickness: a biopsychological perspective. Psychological Topics, 2, 187-200.

Van Hooff, M. L. M., Geurts, S. A. E., Beckers, D. G. J., \& Kompier, M. A. J. (2011). Daily recovery during work and off-job time: the role of activities, effort and pleasure. Work \& Stress, 25, 55-74.

Van Hooff, M. L. M., Geurts, S. A. E., Kompier, M. A. J., \& Taris, T. W. (2007a). Workdays, in-between workdays and the weekend: a diary study on effort and recovery. International Archives of Occupational and Environmental Health, 80, 599-613.

Van Hooff, M. L. M., Geurts, S. A. E., Taris, T. W., \& Kompier, M. A. J. (2007b). "How fatigued do you currently feel?" Convergent and discriminant validity of a single-item fatigue measure. Journal of Occupational Health, 49, 224-234.

Westman, M. (2005). Strategies for coping with business trips: A qualitative exploratory study. International Journal of Stress Management, 11, 167-176.

Westman, M., \& Eden, D. (1997). Effects of a respite from work on burnout: Vacation relief and fade-out. Journal of Applied Psychology, 82, 516-527.

Westman, M., \& Etzion, D. (2001). The impact of vacation and job stress on burnout and absenteeism. Psychology and Health, 16, 95-106.

Wheaton, A. G., Liu, Y., Perry, G. S., \& Croft, J. B. (2011). Effects of short sleep duration on daily activities, United States, 2005-2008. Journal of the American Medical Association, 305, 1956-1957. 